\title{
The hybrid two stage anticlockwise cycle for ecological energy conversion
}

\author{
Piotr Cyklis ${ }^{1, a}$ \\ ${ }^{1}$ Politechnika Krakowska, Department of Mechanical Engineering, Institute of Power and Process Engineering Poland
}

\begin{abstract}
The anticlockwise cycle is commonly used for refrigeration, air conditioning and heat pumps applications. The application of refrigerant in the compression cycle is within the temperature limits of the triple point and the critical point. New refrigerants such as $1234 \mathrm{yf}$ or 1234ze have many disadvantages, therefore natural refrigerants application is favourable. The carbon dioxide and water can be applied only in the hybrid two stages cycle. The possibilities of this solutions are shown for refrigerating applications, as well some experimental results of the adsorption-compression double stages cycle, powered with solar collectors are shown. As a high temperature cycle the adsorption system is applied. The low temperature cycle is the compression stage with carbon dioxide as a working fluid. This allows to achieve relatively high COP for low temperature cycle and for the whole system.
\end{abstract}

\section{Introduction}

The energy conversion, as well as the heat transport from sources of low to high temperatures requires the application of a thermodynamic cycle. The anticlockwise cycle is used for heat transport in refrigeration, air conditioning and heat pumps applications. The most efficient cycle in terms of COP (Coefficient of Performance) is still the compression Linde cycle. The compression cycle requires a refrigerant as a working fluid. Due to the Montreal 1982 and later EU regulations the application of the F-gases as refrigerants is limited. The low ODP (Ozone Depletion Potential), GWP (Global Warming Potential) and TEWI (Total Equivalent Warming Impact) factors substances are needed. The newly developed refrigerants such as R1234yf and others have many disadvantages. This is favourable for natural refrigerants such as carbon dioxide, water and ammonia. However the natural refrigerants have strong temperature application limits. The theoretical application limits for the Linde cycle is within the temperatures of the triple and critical points. Therefore the cooperation of the two energy carriers as for example water and carbon dioxide in the double stage anticlockwise refrigeration cycle is the interesting subject of the investigation and development. In the paper the possibilities of the two stages hybrid ecological refrigerating cycle will be presented. The possibilities of the chosen solutions, as well as some experimental results of the adsorption-compression double stages cycle powered with solar collectors for refrigeration will be shown.

As a high temperature cycle the adsorption system is applied where the waste or renewable energy can be used

\footnotetext{
${ }^{a}$ Corresponding author: pcyklis@mech.pk.edu.pl
}

as the energy source. Using this solution the low COP of the high temperature adsorption cycle is not influencing the total energy consumption. The low temperature cycle is the compression stage with carbon dioxide as a working fluid. This allows to achieve relatively high COP for the low temperature cycle and for the whole system. The system is working at the Laboratory of Thermodynamics and Thermal Machines Measurements. The possibility of the whole year system use (as a heat pump [1], refrigeration and air conditioning setup) makes the economy of the system more economically efficient.

\section{Hybrid double stage cycle}

To apply the $\mathrm{CO}_{2}$ compression system for refrigeration there are two possibilities. First is the one stage compression refrigeration system. In this case the cooling temperature for the ambient air cooled heat exchanger is $45-55^{\circ} \mathrm{C}$. This temperature exceeds the critical point temperature of the $\mathrm{CO}_{2}$, so the condensation is not possible. Therefore the gas cooler instead of the condenser is applied. This has important disadvantages such as: big gas cooler dimensions, low system COP, and high pressure in the gas cooler [2]. Second possibility is the application of the double stages system where $\mathrm{CO}_{2}$ low temperature (LT) stage condenser is cooled by the high temperature (HT) stage evaporator. As the HT stage the other compression cycle (for example R410) may be used, but this requires additional electric power for the HT stage compressor, lowering the total COP of the system. The application of the sorption cycle for the HT stage has many advantages, such as: water as the working fluid, waste 
or renewable heat utilisation, etc. The absorption or the adsorption cycles may be used. One design concept is shown in figure 1 . The absorption $\mathrm{LiBr}-\mathrm{H}_{2} \mathrm{O}$ cycle is applied as the HT stage [3-6]. The advantage of this cycle is the ecology of the working liquid. There are several absorption cycle designs with different COP, shown in figure 2. The disadvantage of the absorption system is that the required desorber temperature is at least $90^{\circ} \mathrm{C}$ for the one effect system [3]. The half effect cycle allows for lower temperature supply, but the efficiency is lower and design and operation is more complicated.

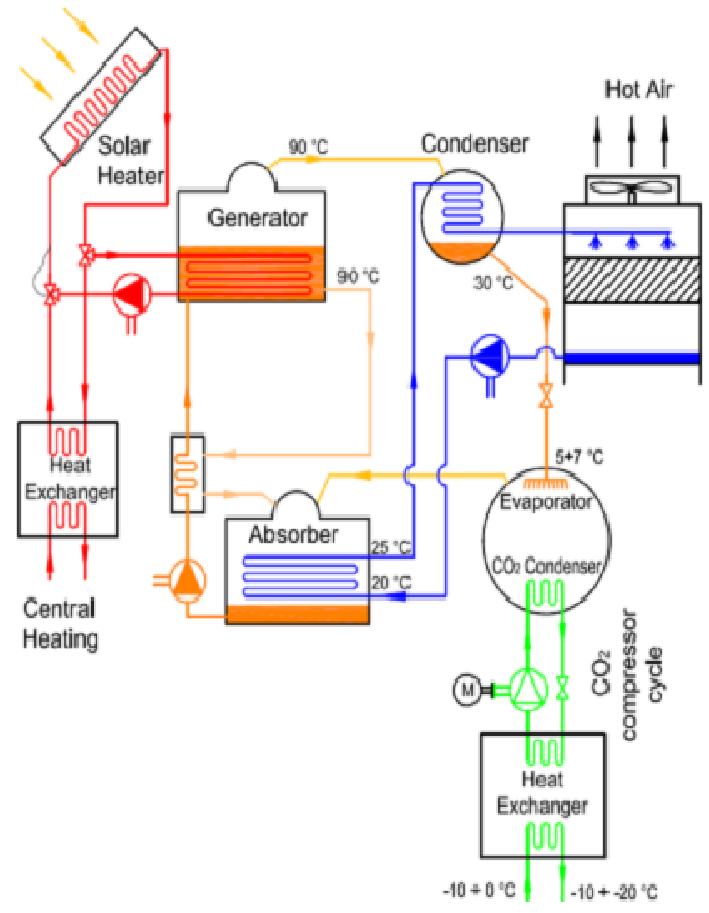

Figure 1. The concept of the ecological hybrid absorptioncompression system [4].

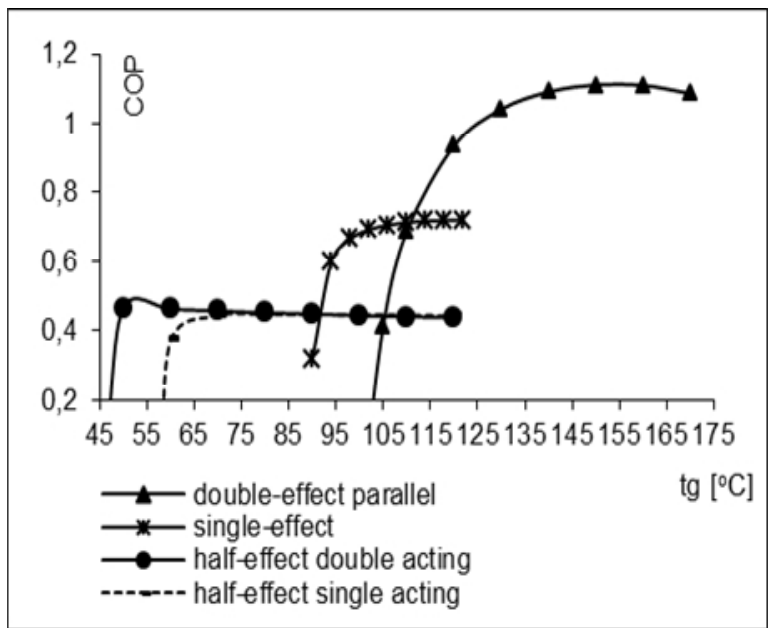

Figure 2. COP of the different HT absorption cycles [3].

If the renewable or waste heat source temperature exceeds $90^{\circ} \mathrm{C}$, the refrigeration absorption cycle shown in figure 1 may be applied with high total COP.

In the Mid-European climate conditions the temperature in the solar collectors is usually low, and frequently the waste heat sources operate with lower temperatures. In this case the HT cycle based on adsorption is more applicable because it may operate with the desorption heat source as low as $55^{\circ} \mathrm{C}[7,8]$.

The concept of the hybrid cascade refrigeration system with the adsorption cycle is presented in figure 3 . In figure 4 the $\mathrm{COP}$ for $75^{\circ} \mathrm{C}$ desorption temperature is shown. The COP for the adsorption system depends of the $t_{\mathrm{m}}$ re-cooling temperature. Therefore the water sprayed cooling tower is the best choice for the recooling.

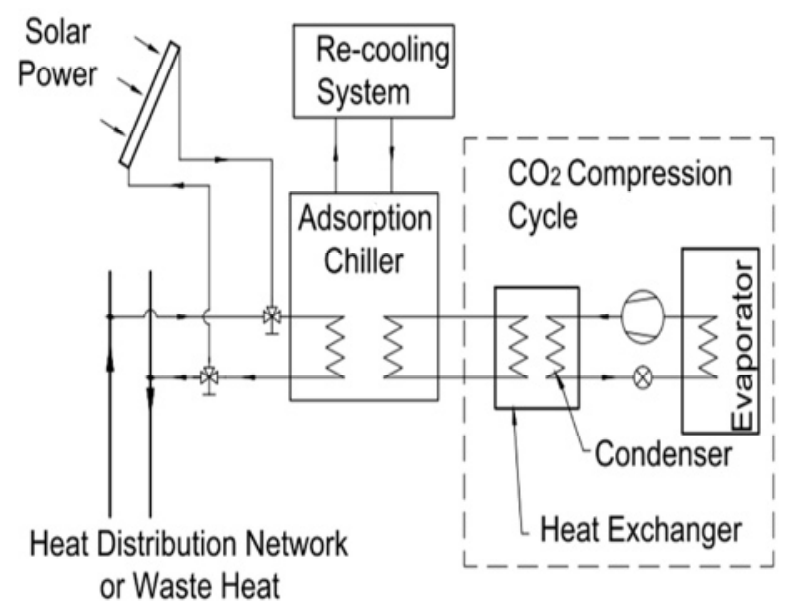

Figure 3. Two stage adsorption compression system for refrigeration [4] [7].

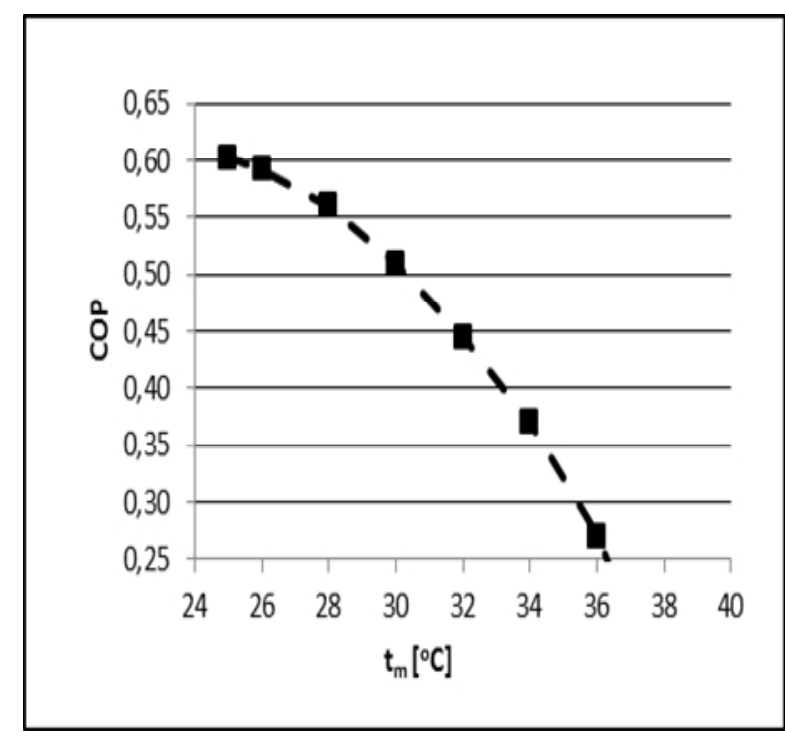

Figure 4. The COP for the adsorption system for the desorption temperature $75^{\circ} \mathrm{C}$ with the respect to the re-cooling temperature.

The efficiency for the adsorption cycle is shown in figure 4 , for $75^{\circ} \mathrm{C}$. The $\mathrm{COP}$ in the shown case is related to the re-cooling temperature, where the heat from the sorption cycle is removed to the ambient air. The adsorption chiller works periodically, with 2,4 or 8 adsorption/desorption beds where the water inflow for cooling or heating of the sorption bed is controlled automatically with the on/off valves, since the adsorption bed is made of solid materials such as for example zeolite. 
Nevertheless the periodic work of the adsorption chiller does not affect the LT stage $\mathrm{CO}_{2}$ condensation [7]. This is due to the thermal capacity of the condenser. The results in terms of TEWI for the hybrid sorption compression system is significantly lower than the result of combined or single stage compression system. The energy efficiency is the challenge, since the compression cycles have higher COP than the sorption systems. Therefore the investigation presented here has been worked out for the energy efficiency comparison.

\section{Laboratory tests}

In the Laboratory of Thermodynamics and Thermal Machines Measurements at the Cracow University of Technology the refrigeration hybrid compression adsorption laboratory stand was built. The main elements are shown in figure 5.

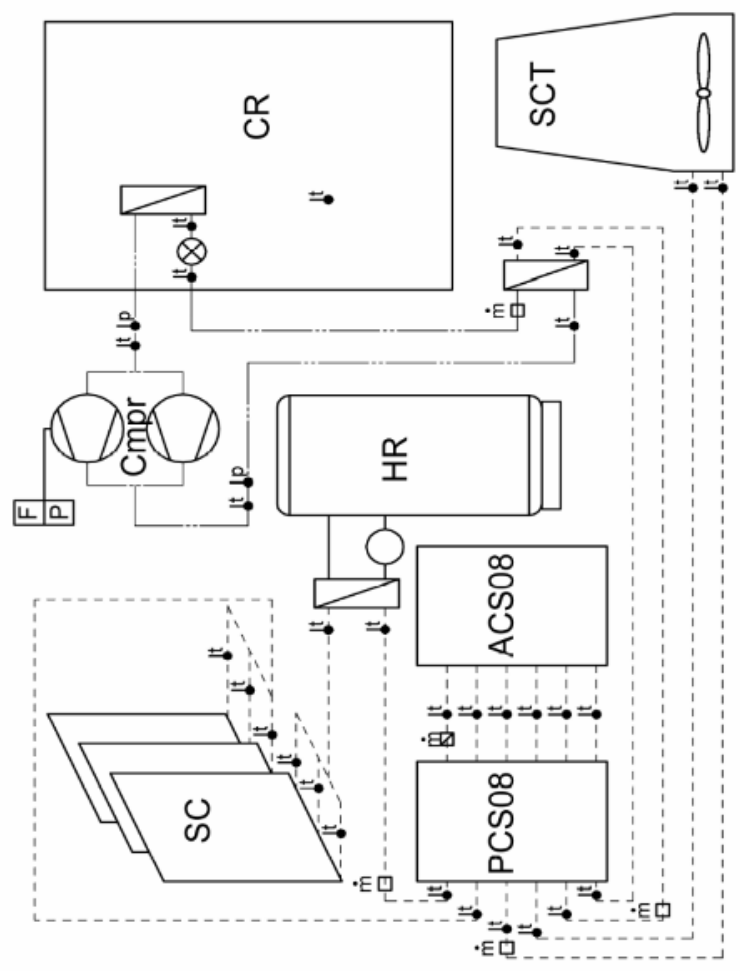

Figure 5. The laboratory stand with hybrid adsorptioncompression cycle for refrigeration. SC- solar collectors, PCS08- pumps with controls and valves, ACS08-adsorption system, Cmpr- compressors, SCT- Sprayed Cooling Tower DECSA REF-C 05, HR- heat reservoir, CR- Refrigeration chamber. Measurements: $t$ - temperature, $\mathrm{m}$-flow, $\mathrm{p}$-pressure.

The details of the system are shown in figs 6,7,8. The adsorption chiller made by Sortech ACS08 [9] is used, for the compression cycle two of the DORIN $\mathrm{CD} 300 \mathrm{H}$ reciprocating compressors are applied. The solar collectors are tube type with about $16 \mathrm{~m}^{2}$ surface area. During the night time when no sun radiation is available the ACS08 unit is switched off and the $\mathrm{CO}_{2}$ condenser is cooled directly from the water sprayed cooling tower DECSA-C05. The system was put into operation in 2011/12 and working until now. During this time the adsorption chiller was changed in 2014 for a newer, more efficient unit Ecocool also by Sortech.

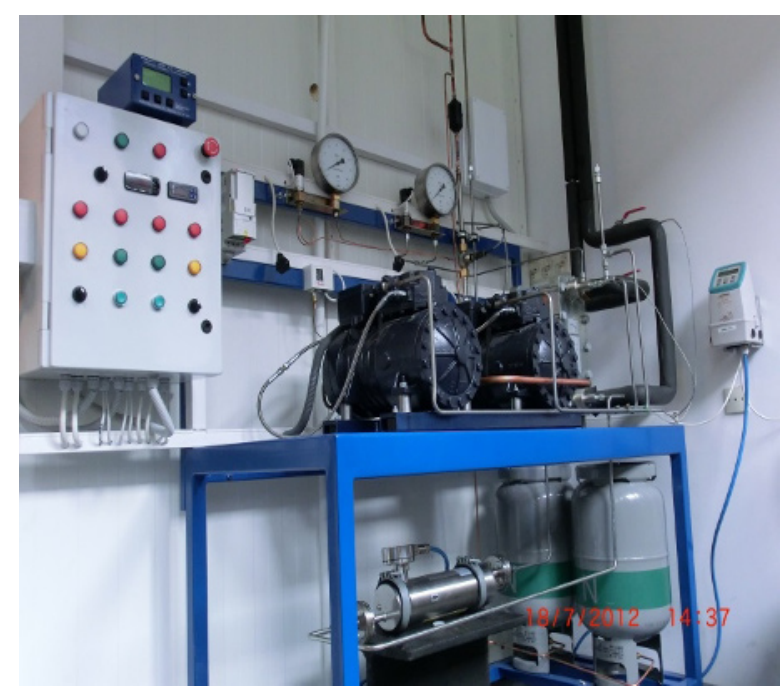

Figure 6. The LT refrigeration compression stage with mass flow meter below, and compressor control case.

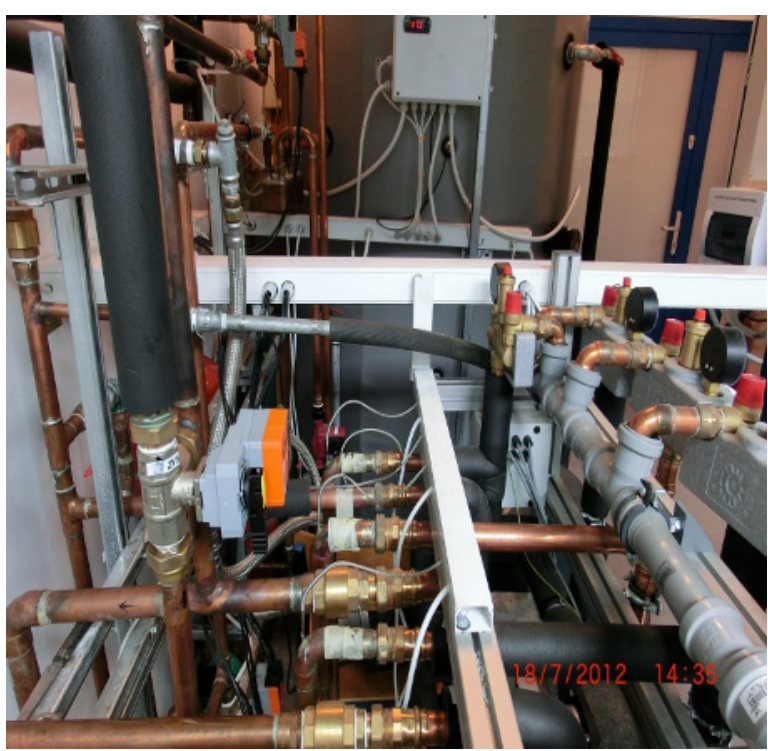

Figure 7. Pipe connections to the HT sorption refrigeration cycle, with thermometers and flow meters.

The measuring equipment used is as follows:

-glycol flow: turbine flow meters HOFFER $\mathrm{HO} 1 / 2 \times 1 / 2$ class of accuracy $0.25 \%$ with impulse meters KEP BATRTM2AC class $0.01 \%$,

$-\mathrm{CO}_{2}$ flow: SIEMENS SITRANS F C MASSFLO 2000 (Coriolis type) class $0.1 \%$ on liquid side,

- Pressure: Vegabar 17 transducers class $0.5 \%$,

- temperature: Pt 100 , current loop class $0.3 \%$,

- electric power: LUMEL M30P-LCTM74 meters class $0.5 \%$.

- Data acquisition system is realized with eight 16-bit ICP DAS measuring cards with range $\pm 20 \mathrm{~mA}$, $0 \sim 20 \mathrm{~mA}, 4 \sim 20 \mathrm{~mA}$ class $0.1 \%$. 

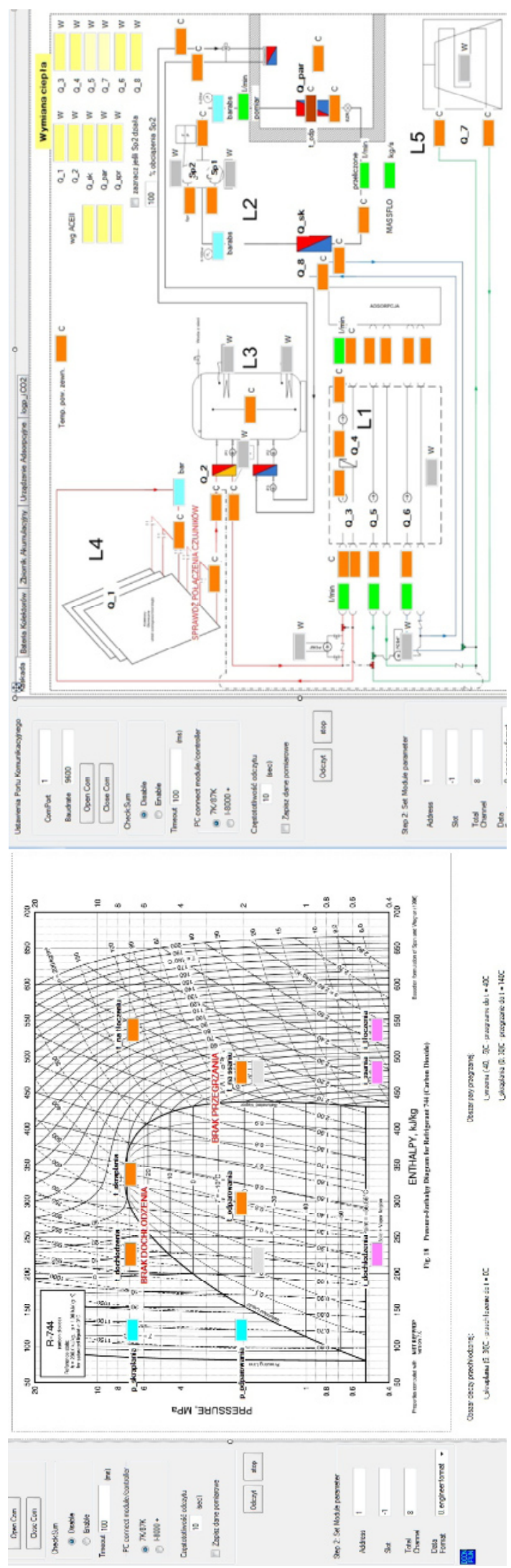

Figure 8. Screen view of the system and its operation (compressor refrigeration cycle shown on the pressure-enthalpy chart.).
- For data acquisition PC software have been prepared with visualization possibilities. The system has been connected via the RS485 port using DCON protocol.

Calculated measurement uncertainty for enthalpy of all liquids better than $4.3 \%$, calculated uncertainty for electric power reading including averaging $1 \%$.

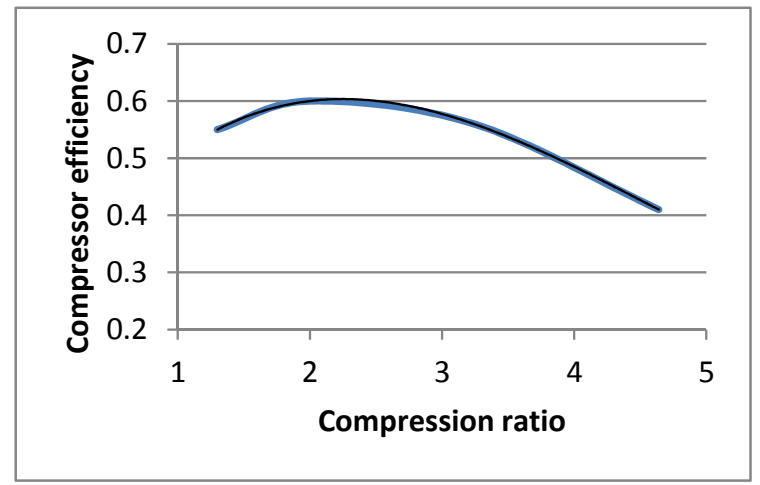

Figure 9. $\mathrm{CO}_{2}$ compressor efficiency related to the compression ratio.

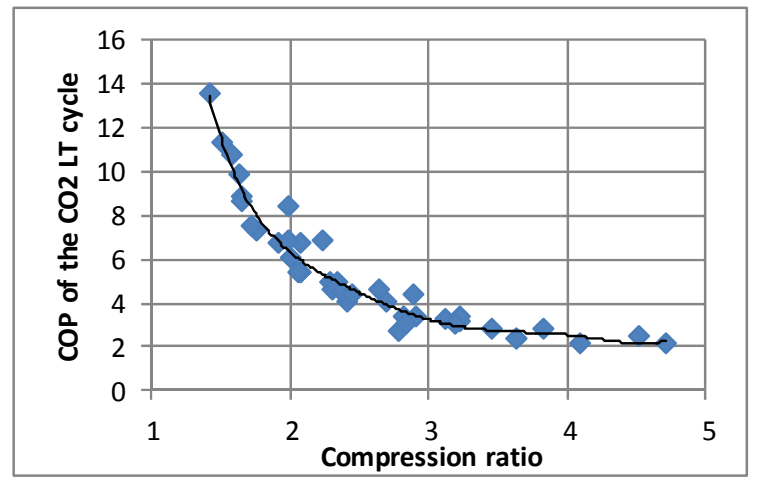

$\overline{\text { Figure 10. The COP of the LT refrigeration compression cycle. }}$

The compressor efficiency calculated on the basis of the measurement results is shown in fig. 9 with the respect to the compression ratio. The real compressor efficiency has a significant influence on the total system COP (Coefficient of Performance), through the LT cycle efficiency. The COP for the compressor refrigeration system means the ratio of the cooling power related to the compressor power. This relation is shown in figure 10 . In case of the full double stage hybrid cycle, the COP is defined as the ratio of the cooling power to the total electric energy supplied for the system. In general this includes also measuring equipment, fans, pumps etc.

The COP calculated on the basis of the experimental results for the presented system is shown in figure 11, compared with two ideal cycles: Carnot cycle and ideal Linde cycle with the compressor efficiency equal to 1 . This chart shows the possibility and limits for increasing the cycle efficiency using better compressors and other possibilities for the real system efficiency improvements. Important part of the system is the automatic control algorithm and design which is shown in the other paper. 


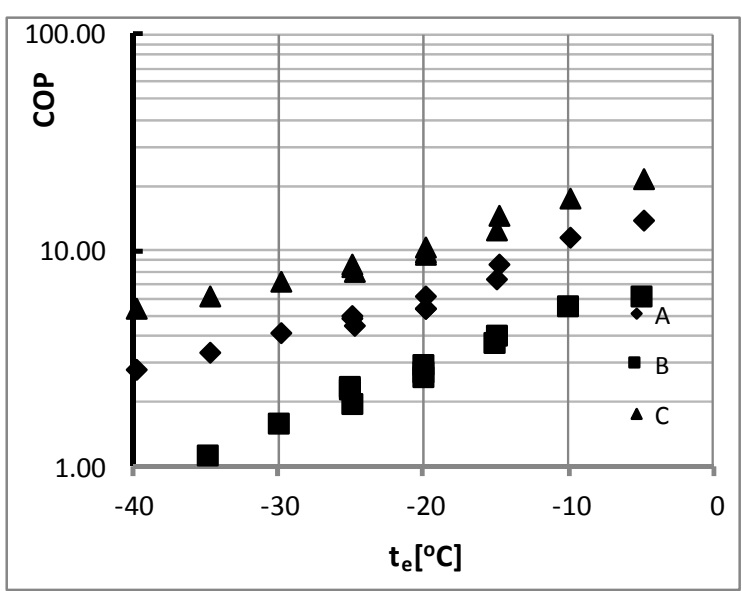

Figure 11. Measured $\mathrm{COP}$ of the $\mathrm{CO}_{2}$ compression cycle comparison for the condenser temperature within $4-7^{\circ} \mathrm{C}$. Acalculated Linde ideal cycle, B - real measured cycle, CCarnot efficiency

\section{Analysis of the results}

For the adsorption systems powered by the solar radiation, the heat container allows to store the solar heat for a few hours only. Therefore during the most part of a night, the $\mathrm{CO}_{2}$ condenser, has to be cooled directly by the cooling tower. In the night in summer the temperature from the cooling tower may be lower than the ambient temperature if the water sprayed cooling tower is applied instead of commonly used dry re-coolers (dry heat exchangers). The condensation temperature in the compression LT cycle rises then, from optimal 3$5^{\circ} \mathrm{C}$ up to $15-25^{\circ} \mathrm{C}$ in Mid-European conditions. In most cases $17-18^{\circ} \mathrm{C}$ was obtained during the tests in hot JuneAugust period in the nights in Poland.

The COP of the $\mathrm{CO}_{2}$ compression cycle is related to the condensation temperature, through the compression ratio and the cycle efficiency.

Five cycles have been compared in figure 12 and 13: a) compression two stage cycle with $\mathrm{CO}_{2}$ and $\mathrm{R} 410 \mathrm{~A}$, b) transcritical $\mathrm{CO}_{2}$ one stage compression cycle,

c) hybrid adsorption-compression with cooling directly from sprayed cooling tower (about $18^{\circ} \mathrm{C}$ in the $\mathrm{CO}_{2}$ condenser),

d) hybrid adsorption-compression with cooling from adsorption (about $5^{\circ} \mathrm{C}$ of $\mathrm{CO}_{2}$ condenser).

e) hybrid adsorption compression as in point d) but with the compression efficiency ideal

The results of the COP calculations for those cycles are shown in figure 12.

Comparison of the two stages systems presented in figs 12 and 13, shows that in most cases the electric energy consumption, which is directly related to the COP, is lower for hybrid system, so in case that the thermal energy is available the hybrid system has all advantages, due to the fact that the TEWI is in each case lower than all other systems.

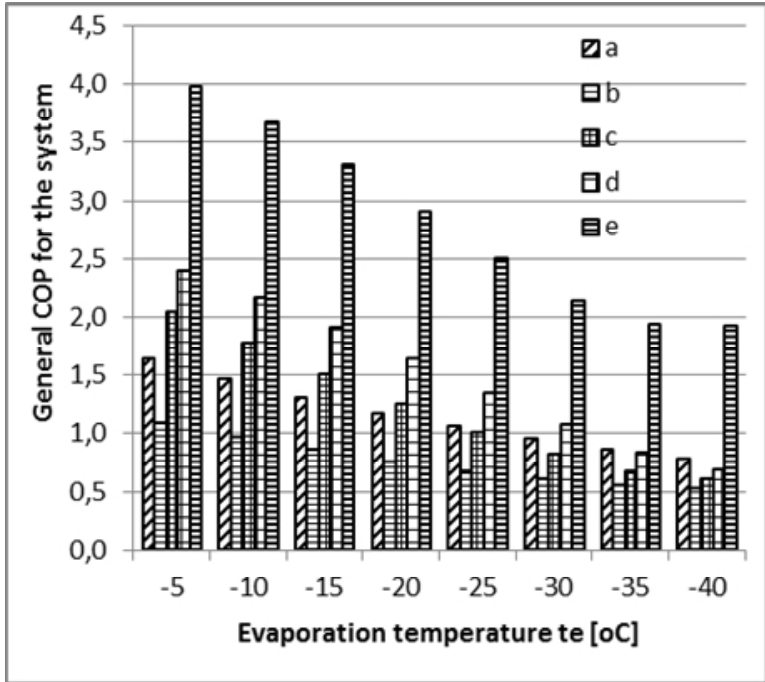

Figure 12. The total COP related to the total electric energy consumption of the system, for five cycles: a-two stages compression $\mathrm{R} 410+\mathrm{CO} 2$, b-transcritical one stage $\mathrm{CO} 2$, c-CO2 compression with the condenser cooled by water sprayed cooling tower, $\mathrm{d}$-double stage hybrid adsorption compression $\mathrm{CO} 2$, e-double stage hybrid with the recalculation for ideal compressor.

The TEWI coefficient was calculated for comparison for the same refrigeration power according to the formula:

$$
\begin{gathered}
T E W I=G W P^{*} L * n+G W P^{*} m *(1-f)+n * E^{*} z \\
E=N * t_{r}
\end{gathered}
$$

Where:

GWP - Global Warming Potential with relationship to $\mathrm{CO}_{2}$,

$L \quad$ - emission to the atmosphere $(\mathrm{kg} / \mathrm{yr})$,

$n \quad$ - life of the cycle (yr),

$m$ - amount of refrigerant in installation $(\mathrm{kg})$,

$f \quad$ - recovery of the refrigerant (-),

$E \quad$ - energy use of the cycle per year (kWh),

$z \quad-\mathrm{CO}_{2}$ emission for the electric energy; Poland $z=0,94\left(\mathrm{kgCO}_{2} / \mathrm{kWh}\right)$,

$N$ - supplied electric power of the cycle $(\mathrm{kW})$,

$t_{r} \quad$ - yearly number of working hours (h).

(Better TEWI means lower value, better COP means higher value)

Another comparison for the refrigeration system is the hybrid system compared to the one stage refrigerating compressor system with the commonly used $\mathrm{R} 407 \mathrm{C}$ refrigerant.

The energy - COP comparison is shown in figure 14, and ecological -TEWI comparison in figure 15 . The comparison is shown for the wide range of evaporation temperatures. The practical refrigerating application for the hybrid system is the condensing temperature $5-10^{\circ} \mathrm{C}$. For the one stage refrigerating compressor cycle the real condensation temperature with the air cooled condenser is about $40-45^{\circ} \mathrm{C}$. 


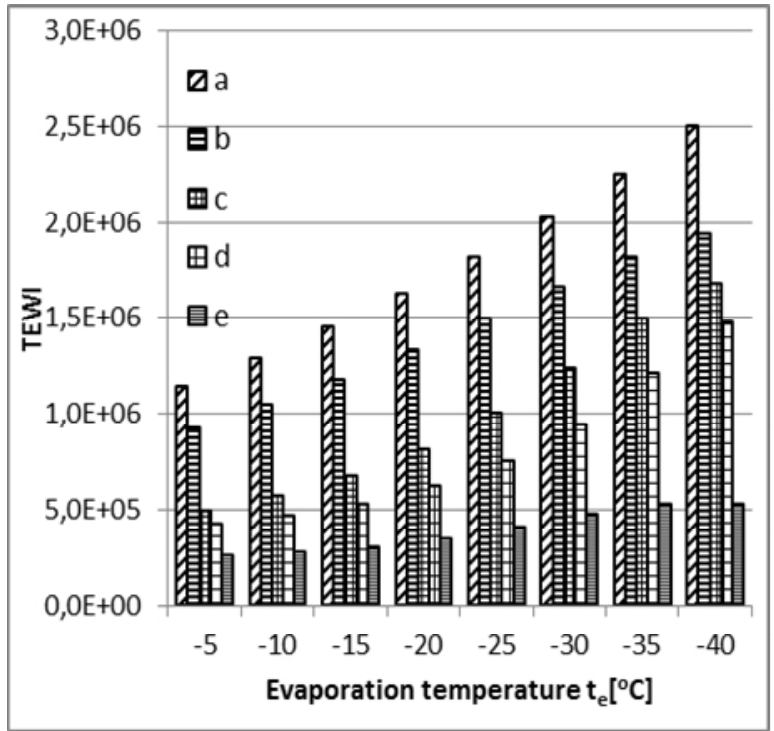

Figure 13. TEWI coefficient for five cycles: a-two stages compression $\mathrm{R} 410+\mathrm{CO}_{2}$, b-transcritical one stage $\mathrm{CO}_{2}, \mathrm{c}-\mathrm{CO}_{2}$ compression with the condenser cooled by water sprayed cooling tower, $\mathrm{d}$-double stage hybrid adsorption compression $\mathrm{CO}_{2}$, e-double stage hybrid with the recalculation for ideal compressor.

As an addition other condensing temperatures are depicted in fig 14 and 15 . It can be noticed that the COP of the hybrid system is higher than one stage R407C compression system in each case when the condensing temperature comes from air heat exchanger $\left(45^{\circ} \mathrm{C}\right)$ and for ice water cooling $\left(10^{\circ} \mathrm{C}\right)$ the carbon dioxide compression cycle is more efficient below evaporation temperature $-25^{\circ} \mathrm{C}$. In each case TEWI index is lower for the investigated hybrid system.

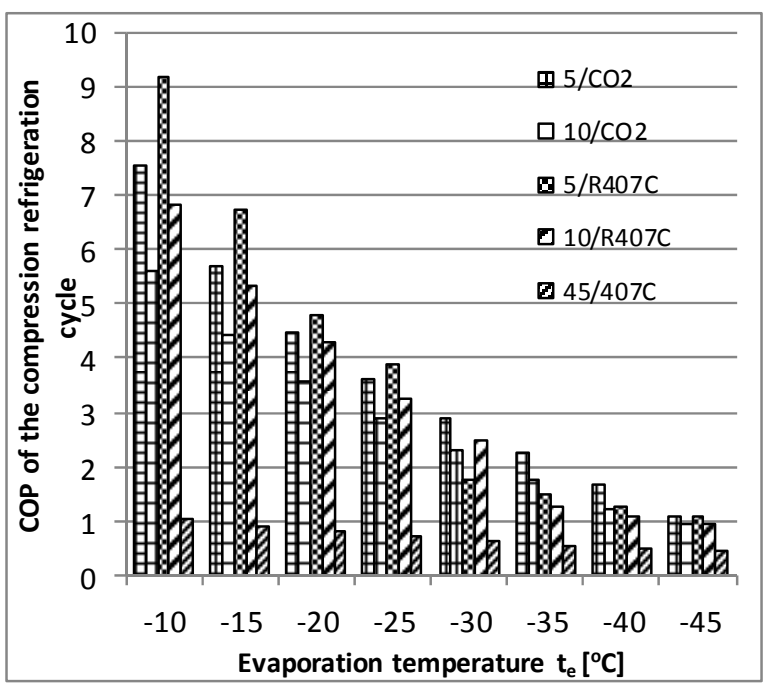

Figure 14. The COP coefficient of the compression refrigeration cycle related to the evaporation temperature for: $5 / \mathrm{CO} 2-\mathrm{CO}_{2}$ cycle with condensation temperature $5^{\circ} \mathrm{C}$, $10 / \mathrm{CO} 2$-for condensation temperature $10^{\circ} \mathrm{C}$, 5/R407C,10/R407C,45/R407C R407 compressor refrigeration cycle for evaporation temperature respectively $5,10,45^{\circ} \mathrm{C}$.

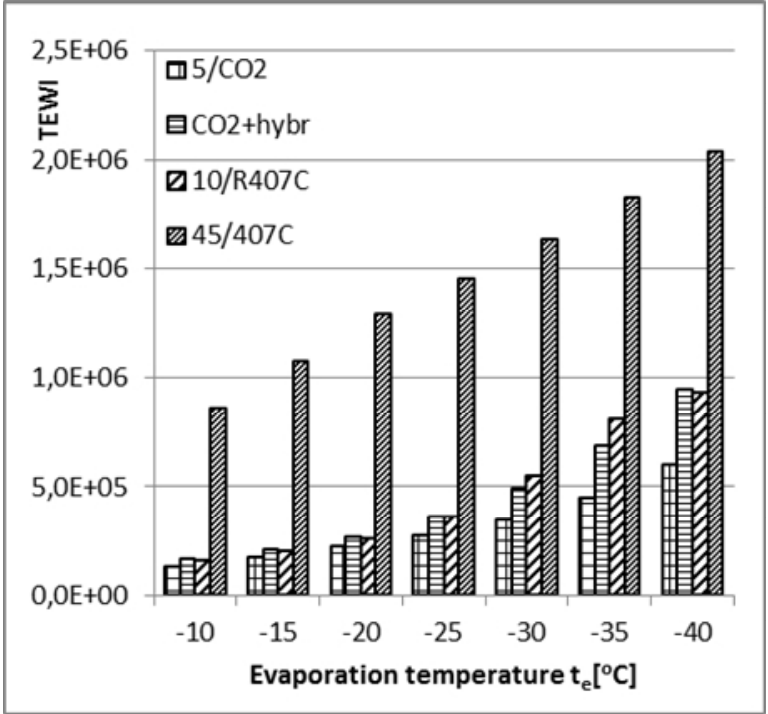

Figure 15. TEWI comparison for ecological hybrid $\mathrm{CO}_{2}$ and adsorption cycle and one stage refrigeration compression cycle with popular R407C.

\section{Conclusions}

The sorption refrigeration cycles are still popular due to the possibility of the low temperature waste or renewable heat utilisation. In Asia, Australia and USA adsorption systems are commonly used, while in Europe the absorption systems are more popular. The absorption and adsorption systems are used usually for the air conditioning purposes or ice water production, however the possibilities of the application of the sorption technology in refrigeration is much wider. Due to the lack of the really non-harmful refrigerants and temperature limits for carbon dioxide, the application of the hybrid systems combining $\mathrm{CO}_{2}$ compression cycle and adsorption HT is welcome. They can be used in refrigeration where the required evaporation temperature is $-45^{\circ} \mathrm{C}$ up to $-15^{\circ} \mathrm{C}$. Properly designed hybrid refrigeration system assures both ecology and economy benefits. This investigation shows that when needed temperature for the evaporation is lower than $-25^{\circ} \mathrm{C}$ the hybrid system has higher COP than commonly used refrigerants $\mathrm{R} 407 \mathrm{C}$ or R410 single or double stage, even when the R407C cycle is ice water cooled. The water sprayed cooling tower allows for system operation when the HT cycle heat source is limited, without exceeding the critical point temperature. This makes it possible to operate the system powered by the solar radiation. In this case during the day the $\mathrm{CO}_{2}$ condenser is powered by solar collectors and during the night or colder weather the cooling tower is enough to keep the temperature of the evaporator below $20^{\circ} \mathrm{C}$. The total COP of the system is in this case lower, but the TEWI coefficient is always better. The flexibility of the cycles combination allows for different solutions such as additional air conditioning when HT adsorption cycle has higher cooling power than the refrigeration cycle. In winter time adsorption cycle may be reversed and used for heating as a heat pump. This makes the system more economically efficient. 


\section{Acknowledgements}

This project has been sponsored by the Polish National Centre of Research and Development within grant no.: N R06 000210 0936/R/T02/2010/10

\section{References}

1. A. Grzebielec, Archives of thermodynamics 30, (2009)

2. Y. Hiroshi and Z. Xin-Rong, International Journal of Refrigeration 32, (2009)

3. P. Cyklis and G. Brak, Transactions of the Institute of Fluid-Flow Machinery 121, (2008)

4. P. Cyklis and R. Kantor, XXIII International Congress of Refrigeration, proceedings, Prague, Czech Republic, August (2011)

5. Z. Danxing and M. Xuelin, Energy Conversion and Management 56, (2012)

6. H. Wei, S. Liuli, D. Zheng, J. Hongguang, M. Sijun and J. Xuye, Applied Energy 106, (2013)

7. P. Cyklis, International Journal of Refrigeration, 48,(2014)

8. B. Saha, L. El-Sharkawya, A. Chakrabortya, S. Koyama, N. Banker, P. Duttab, M. Prasad I K. Srinivasana, International Journal of Refrigeration 29, (2006)

9. SorTech, ,SorTech Adsorption Chiller ACS 08/ACS 15, Design manual, Version 2.2, SorTech, Halle, (2009) 